\title{
Quantitative analyzing for As's transferring process in coastal waters in Jiaozhou Bay
}

\author{
Dongfang Yang ${ }^{1,2,3, *}$, Qiang Wang ${ }^{1,2}$, Wei Zhou ${ }^{1,2}$, Chunhua Su ${ }^{1,2}$, and Sixi Zhu1,2 \\ ${ }^{1}$ Research Center for Karst Wetland Ecology, Guizhou Minzu University, Guizhou Guiyang, Guizhou Guiyang, China \\ ${ }^{2}$ College of Chemistry and Environmental Science, Guizhou Minzu University, Shanghai, 550025, China \\ ${ }^{3}$ North China Sea Environmental Monitoring Center, SOA, Qingdao 266033, China
}

\begin{abstract}
This paper quantified the horizontal and vertical transferring processes of As in coastal waters in the southwest and the bay mouth of Jiaozhou Bay using investigation data in July and October 1982. Results showed that the horizontal absolute loss amounts of As contents in surface waters were $0.20-2.44 \mu \mathrm{g} \mathrm{L}^{-1}$, and the horizontal relative loss amounts in surface waters were $19.23 \%-87.14 \%$, respectively. The horizontal absolute loss amounts of As contents in bottom waters were $0.27-2.44 \mu \mathrm{g} \mathrm{L}^{-1}$, and the horizontal relative loss amounts in bottom waters were $25.00 \%-54.46 \%$, respectively. The vertical absolute dilution amounts of As contents were $0.02-0.28 \mu \mathrm{g} \mathrm{L}^{-1}$, and the vertical relative dilution amounts were $1.78-16.66 \%$. The vertical absolute accumulation amounts of $\mathrm{Pb}$ contents were $0.10-0.86 \mu \mathrm{g} \mathrm{L}^{-1}$, and the vertical relative accumulation amounts were $7.35 \%-35.83 \%$. The vertical absolute dilution amount and vertical relative dilution amount of As's contents were $0.20-0.76 \mu \mathrm{g} \mathrm{L}^{-1}$ and $19.23 \%-27.14 \%$, respectively. The vertical absolute accumulation amount and vertical relative accumulation amount of As's contents were 0.28-4.12 $\mu \mathrm{g} \mathrm{L}^{-1}$ and $25.00 \%-91.96 \%$, respectively. The changes of As contents in surface and bottom waters were determined by the source inputs of As and the transferring distance of As from the terrisgenous sources.
\end{abstract}

\section{Introduction}

As has been widely used industry and agriculture, yet the excessive existence of As in the environment is harmful to organism and ecosystem since As is high toxic ([1-2]). Nowadays, many marine bays have been polluted by As ([3-6]). Understanding the transferring processes of As in marine bays is essential to pollution control. Jiaozhou Bay is a semi-closed bay located in Shandong Province China, and has been polluted by various pollutants including As in the past three decades ([1-2]). This paper quantified the horizontal and vertical transferring processes of As in coastal waters in the southwest and the bay mouth of Jiaozhou Bay using investigation data in July and October 1982. The aim of this paper was to better understand the transporting processes of As in marine bay, and provide basis for scientific research and environment remediation.

\section{Materials and method}

\subsection{Study area}

Jiaozhou Bay is located in the south of Shandong Province, eastern China $\left(35^{\circ} 55^{\prime}-36^{\circ} 18^{\prime} \mathrm{N}, 120^{\circ} 04^{\prime}-\right.$ $120^{\circ} 23^{\prime}$ E). The total area, average water depth and the width of the bay mouth are $446 \mathrm{~km} 2,7 \mathrm{~m}$ and $3 \mathrm{~km}$, respectively. The bay mouth is connecting to the Yellow
Sea in the south, and is surrounded by Qingdao, Jiaozhou and Jiaonan in the east, north and west, respectively (Fig. 1). There are a dozen of rivers, all of which are seasonal rivers ([7-8]).

\subsection{Data collection}

The investigation on As in surface and bottom waters in coastal waters in Jiaozhou Bay was carried on in July and October 1982 in four sampling sites (i.e., 083, 084, 122 and 123) (Fig. 1). As in waters was sampled and monitored follow by National Specification for Marine Monitoring ([9]).

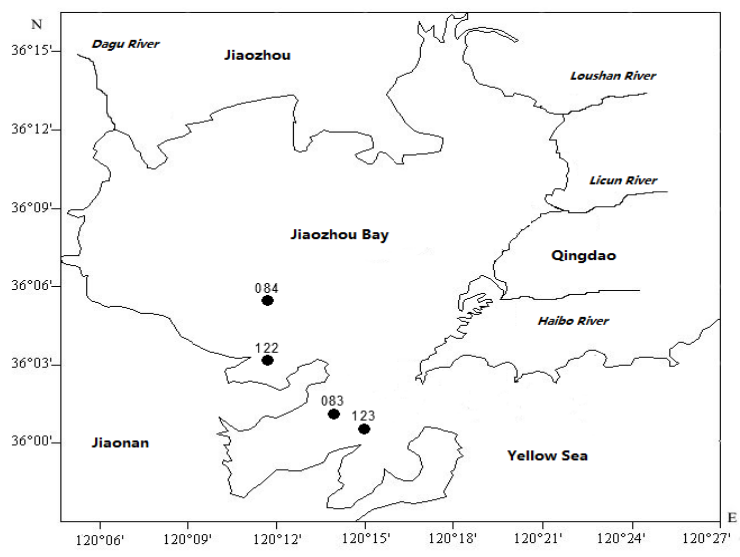

Fig. 1. Geographic location and monitoring sites in Jiaozhou Bay.

\footnotetext{
* Corresponding author: dfyang_dfyang@,126.com
} 


\subsection{Modelling for horizontal transferring processes of As}

Supposed that certain substance's contents in surface and bottom waters in the coastal waters in the southwest of bay were $A$ and $a$, in the center waters in the southwest of the bay was $\mathrm{B}$ and $b$, respectively ([10]). In surface waters, and from the coastal waters in the southwest of bay to the center waters in the southwest of the bay, and the calculation formula for transferring process is:

$$
D=A-B, \quad E=(100 \times|A-B| / \max (A, B)) \%
$$

where, $D$ is the horizontal absolute loss amount in surface waters from the inner of the bay to the open waters, $E$ is the corresponding horizontal relative loss amount in surface waters.

In bottom waters, and from the inner of the bay to the open waters, substance's contents are changing, and the calculation formula for transferring process is:

$$
d=a-b, \quad e=(100 \times|a-b| / \max (a, b)) \%
$$

where, $d$ is the horizontal absolute loss amount in surface waters, $e$ is the corresponding horizontal relative loss amount in surface waters.

\subsection{Modelling for vertical transferring processes of As}

Supposed that certain substance's contents in surface and bottom waters in Site $n$ in the coastal waters in the southwest of the bay are $A$ and $a$, respectively. From surface waters to bottom waters, the calculation formula for this transferring process is:

$$
V_{n a}=A-a, \quad V_{n r}=(100 \times|A-a| / \max (A, a)) \%
$$

where, $V_{n a}$ is the horizontal absolute dilution amount, $V_{n r}$ is the corresponding horizontal relative dilution amount. While from bottom waters to surface waters, $V_{n a}$ refers to the horizontal absolute accumulation amount, and $V_{n r}$ refers to the corresponding horizontal relative accumulation amount.

\section{Results and discussion}

\subsection{Horizontal and vertical transferring processes of As}

As's contents in Site 122 and 084 were used to quantify the horizontal and vertical transferring processes of As. In according to Eq. (1) and (2), the horizontal loss of As in surface and waters were calculated listed in Table 1. As's contents in surface and bottom waters in Site 122 and 084 were used to quantify the vertical dilution and accumulation processes of As. In according to Eq. (3), the vertical dilution and accumulation of As were calculated listed in Table 2.

Table 1. Horizontal loss of As in surface and bottom waters in Jiaozhou Bay 1982

\begin{tabular}{|c|c|c|c|c|}
\hline \multirow{2}{*}{ Month } & \multicolumn{2}{|c|}{ Surface waters } & \multicolumn{2}{c|}{ Bottom waters } \\
\cline { 2 - 5 } & $D / \mu \mathrm{g} \mathrm{L}^{-1}$ & $E / \%$ & $d / \mu \mathrm{g} \mathrm{L}$ & $e / \%$ \\
\hline July & 2.44 & 87.14 & -2.44 & 54.46 \\
\hline $\begin{array}{c}\text { Octob } \\
\text { er }\end{array}$ & 0.20 & 19.23 & -0.28 & 25.00 \\
\hline
\end{tabular}

Table 2. Vertical dilution and accumulation processes of As in Jiaozhou Bay 1982

\begin{tabular}{|c|c|c|c|}
\hline Time & Waters & $V_{n a} / \mu \mathrm{g} \mathrm{L}^{-1}$ & $V n r / \%$ \\
\hline July & $\begin{array}{c}\text { Coastal waters } \\
\text { in the southwest }\end{array}$ & 0.76 & 27.14 \\
\cline { 2 - 4 } & $\begin{array}{c}\text { Center waters in } \\
\text { the southwest }\end{array}$ & -4.12 & 91.96 \\
\hline $\begin{array}{c}\text { Octo } \\
\text { ber }\end{array}$ & $\begin{array}{c}\text { Coastal waters } \\
\text { in the southwest }\end{array}$ & 0.20 & 19.23 \\
\cline { 2 - 4 } & $\begin{array}{c}\text { Center waters in } \\
\text { the southwest }\end{array}$ & -0.28 & 25.00 \\
\hline
\end{tabular}

In July 1982, the horizontal absolute loss amount in surface waters was as high as $87.14 \%$, while the horizontal absolute loss amount in bottom waters was $54.46 \%$ (Fig. 2). The vertical relative dilution amount was relative low in coastal waters (27.14), yet in the center of waters in the southwest of the bay the vertical relative accumulation was very high $(91.96 \%)$ (Fig. 2).

In October 1982, the horizontal absolute loss amount in surface waters was relative low as $19.23 \%$, and the horizontal absolute loss amount in bottom waters was also relative low as $25.00 \%$ (Fig. 3). The vertical relative dilution amount was relative low in coastal waters $(19.23 \%)$, while in the center of waters in the southwest of the bay the vertical relative accumulation was also relative low (25.00\%) (Fig. 3).

In general, the horizontal absolute loss amounts of As contents in surface waters were $0.20-2.44 \mu \mathrm{g} \mathrm{L}^{-1}$, and the horizontal relative loss amounts in surface waters were $19.23 \%-87.14 \%$, respectively. The horizontal absolute loss amounts of As contents in bottom waters were 0.27 $2.44 \mu \mathrm{g} \mathrm{L}^{-1}$, and the horizontal relative loss amounts in bottom waters were $25.00 \%-54.46 \%$, respectively.

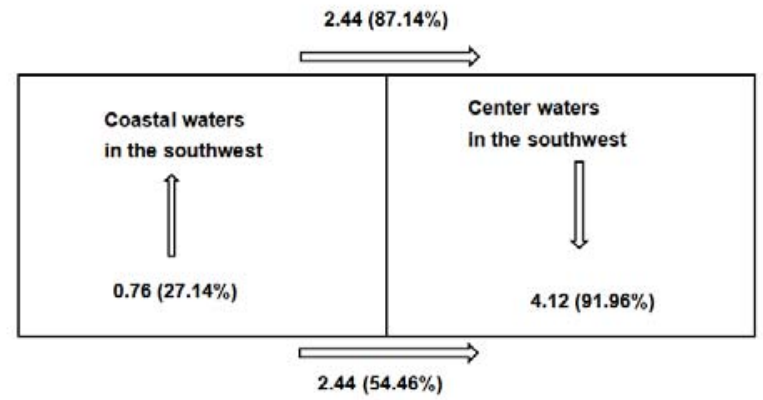

Fig. 2. Block diagram for horizontal-vertical changes of As in Jiaozhou Bay in July 1982 


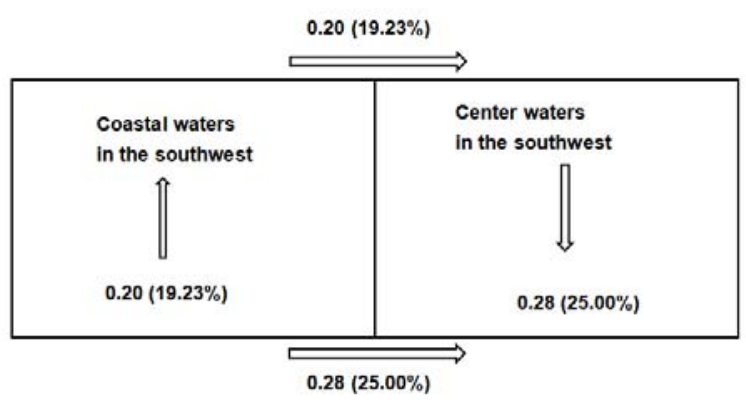

Fig. 3. Block diagram for horizontal-vertical changes of As in Jiaozhou Bay in October 1982

\subsection{Horizontal loss of As in coastal waters}

In July 1982, the horizontal loss of As's contents in surface waters from the coastal waters in the southwest of the bay to the center waters in the southwest was very high $(87.14 \%)$, and in bottom waters was also relative high $(54.46 \%)$. The vertical dilution amount was relative low in coastal waters in the southwest of the bay (27.14\%), while the vertical accumulation amount was very high in center waters in the southwest of the bay $(91.96 \%)$.

In October 1982, the horizontal loss of As's contents in surface waters from the coastal waters in the southwest of the bay to the center waters in the southwest was relative low $(19.23 \%)$, and in bottom waters was also relative low $(25.00 \%)$. The vertical dilution amount was relative low in coastal waters in the southwest of the bay $(19.23 \%)$, and the vertical accumulation amount was also relative low in center waters in the southwest of the bay $(25.00 \%)$.

In general, there was relative dilution process in coastal waters in coastal waters, while in the center of the southwest of the bay there were relative high or relative low accumulation processes. There were horizontal loss processes in both surface and bottom waters from coastal waters in the southwest to the center waters in the southwest of the bay. The horizontal loss of As's contents were relative high in both surface and bottom waters in July 1982, while in October 1982 the horizontal loss was relative low in bottom waters.

\subsection{Spatial variations of As in coastal waters}

In July 1982, the horizontal loss of As's contents in surface waters from the coastal waters in the southwest of the bay to the center waters in the southwest was very high $(87.14 \%)$, and in bottom waters was also relative high $(54.46 \%)$. The vertical dilution amount was relative low in coastal waters in the southwest of the bay (27.14\%), while the vertical accumulation amount was very high in center waters in the southwest of the bay (91.96\%). In order to reveal the spatial variations of As, for each sampling site (i.e., 083, 084, 122 and 123), As content in surface waters was subtracted by which in bottom waters.

In July 1982, the differences ranged from -4.12-1.72 $\mu \mathrm{g} \mathrm{L}-1$. The difference was negative in Site 084 in the center waters in the southwest of the bay, while the differences in the other three sampling sites were all positive (Table 3). In October 1982, the differences ranged from $-0.54-0.46 \mu \mathrm{g} \mathrm{L}-1$. The differences were negative in Site 083 and 084 in the center waters in the southwest of the bay, while the differences in the other three sampling sites were all positive (Table 3).

In general, the changes of As contents in surface and bottom waters were determined by the source inputs of As and the transferring distance of As from the terrisgenous sources. In locations closed to the terrigenous sources and the sedimentation of As was still in low level, the dilution amount was small, resulted in As contents in surface waters were higher than in bottom waters. Once As had been transferred fay away from the terrisgenous sources, the sedimentation of As was abundant, resulted in As contents in surface waters were lower than in bottom waters.

Table 3 Spatial variations of As in Jiaozhou Bay 1982

\begin{tabular}{ccccc}
\hline Time & Site 122 & Site 084 & Site 083 & Site 123 \\
\hline July & Positive & Negative & Positive & Positive \\
Positive & Positive & Negative & $\begin{array}{c}\text { Negativ } \\
\text { e }\end{array}$ & Positive \\
& & & \\
\hline
\end{tabular}

\section{Conclusions}

The horizontal and vertical transferring processes of As in coastal waters in the southwest and the bay mouth of Jiaozhou Bay 1982 were quantitatively analyzed. The horizontal absolute loss amounts of As contents in surface waters were $0.20-2.44 \mu \mathrm{g} \mathrm{L}^{-1}$, and the horizontal relative loss amounts in surface waters were $19.23 \%$ $87.14 \%$, respectively. The horizontal absolute loss amounts of As contents in bottom waters were 0.27-2.44

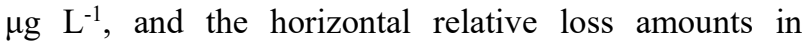
bottom waters were $25.00 \%-54.46 \%$, respectively.

There was relative dilution process in coastal waters in coastal waters, while in the center of the southwest of the bay there were relative high or relative low accumulation processes. There were horizontal loss processes in both surface and bottom waters from coastal waters in the southwest to the center waters in the southwest of the bay. The horizontal loss of As's contents were relative high in both surface and bottom waters in July 1982, while in October 1982 the horizontal loss was relative low in bottom waters. The changes of As contents in surface and bottom waters were determined by the source inputs of As and the transferring distance of As from the terrisgenous sources.

\section{Acknowledgments}

This research was sponsored by Research Projects of Guizhou Nationalities University ([2014]02), Research Projects of Guizhou Province Ministry of Education (KY [2014] 266), Research Projects of Guizhou Province Ministry of Science and Technology (LH [2014] 7376).

\section{References}


1. D.F. Yang, W.P. Song, S.T. Chen, J.H. Guo, L. Zheng, Coastal Engineering, 31, 4(2012)

2. D.F. Yang, Y.H. Zhao, Z.G. Piao, Ocean Development and Management, 31, (2014)

3. D.F. Yang, S.X. Zhu, F.Y. Wang, S.T. Chen, Z.J. $\mathrm{Xu}$, S.X. Zhu, Y.J. Wu, Meterological and Environmental Research, 5, (2014)

4. D.F. Yang, F.Y. Wang, H.Z. He, Y.J. Wu, S.X. Zhu, Proceedings of the 2015 international symposium on computers and informatics, (2015)

5. D.F. Yang, F.Y. Wang, X.L. ZhaoY.J. Wu, S.X. Zhu, Sustainable Energy and Enviroment Protection, (2015)

6. D.F. Yang, F.Y. Wang, X.Q. Yang, Y.J. Wu, S.X. Zhu, Advances in Computer Science Research, 3252, (2015)

7. D.F. Yang, Y. Chen, Z.H. Gao, J. Zhang, F. Wang, Chinese Journal of Oceanology and Limnology, 23, 1(2005)

8. D.F. Yang, F.Y. Wang, Z.H. Gao, W.L. Cui, S.X. Huo, Marine Science, 28, 6(2004)

9. China's State Oceanic Administration, The specification for marine monitoring (Ocean Press, Beijiang, 1991)

10. Yang DF, Miao ZQ, Xu HZ, Y. Chen, J.Y. Sun, Marine Environmental Science, 32, 3(2013) 